\title{
Değerli Metal Katalizörlerde Katalizör Destek Malzemesi Olarak Biyotabanlı Malzemelerin Üretilmesi ve Karakterizasyonu
}

\author{
Elif Yaman ${ }^{1 *}$, Fatma Özge Gökmen ${ }^{2}$, Sinan Temel ${ }^{3}$, Nurgül Özbay ${ }^{4}$, Gamzenur Özsin $^{5}$ \\ ${ }^{1}$ Bilecik Şeyh Edebali Üniversitesi, Merkezi Araştırma Laboratuvarı, Bilecik, Türkiye (ORCID: 0000-0002-1052-8779) elif.yaman@bilecik.edu.tr \\ 2 Bilecik Şeyh Edebali Üniversitesi, Merkezi Araştırma Laboratuvarı, Bilecik, Türkiye (ORCID: 0000-0002-5548-8790) fatmaozge.gokmen@bilecik.edu.tr \\ 3 Bilecik Şeyh Edebali Üniversitesi, Merkezi Araştırma Laboratuvarı, Bilecik, Türkiye (ORCID: 0000-0002-0889-9490) Sinan.temel@bilecik.edu.tr \\ ${ }^{4}$ Bilecik Şeyh Edebali Üniversitesi, Kimya Mühendisliği Bölümü, Bilecik. Türkiye (ORCID: 0000-0002-0666-3417) nurgul.ozbay@bilecik.edu.tr \\ 5 Bilecik Şeyh Edebali Üniversitesi, Kimya Mühendisliği Bölümü, Bilecik. Türkiye (ORCID: 0000-0001-5091-5485) gamzenur.ozsin@bilecik.edu.tr
}

(İlk Geliş Tarihi 11 Ocak 2021 ve Kabul Tarihi 20 Mart 2021)

(DOI: 10.31590 /ejosat.858676)

ATIF/REFERENCE: Yaman, E., Gökmen, F. Ö., Temel, S., Özbay, N. \& Özsin, G. (2021). Değerli Metal Katalizörlerde Katalizör Destek Malzemesi Olarak Biyotabanlı Malzemelerin Üretilmesi ve Karakterizasyonu. Avrupa Bilim ve Teknoloji Dergisi, (23), $181-188$.

\section{$\ddot{O ̈ z}$}

Katalizörler kimya endüstrisinde geniş bir alanda kullanılan ve kullanıldığı sektörde maliyeti artıran en önemli kalemlerden biridir. Özellikle değerli metallerin katalizör olarak kullanıldığı reaksiyonlarda katalizör destek malzemesinin kullanılması, katalizör maliyetinin azaltılması için önem arz etmektedir. Karbonlu malzemeler katalizör desteği için istenen özellikleri sağlaması nedeniyle heterojen kataliz reaksiyonlarında uzun süredir kullanılmaktadır ve bu malzemelerin biyokütle gibi sürdürülebilir ve yenilenebilir bir kaynaktan elde edilebilmesi önemlidir. Yapılan bu çalışmada, göknar ağacı talaşından biyotabanlı malzeme elde edilmesi ve bu malzemelerin karbonlu katalizör destek malzemesi olarak kullanılabilirliği araştırılmıştır. Çalışmada termokimyasal yöntemler olan karbonizasyon yöntemi ile biyochar; hidrotermal karbonizasyon yöntemi ile de hidrochar elde edilmiştir. Hem ham biyokütleye, hem de biyochar ve hidrochar örneklerine değerli metallerden olan Pt ve Pd kütlece \%1 oranında yüklenmiştir. Elde edilen katalizör örneklerinin fizikokimyasal ve yüzey özellikleri farklı teknikler kullanılarak incelenmiş ve elde edilen sonuçlara göre, biyokütlenin katalizör desteği olarak doğrudan kullanılması için uygun özelliklere sahip olmadığ belirlenmiştir. Metal yüklenen biyochar ve hidrocharın katalizör özellikleri incelendiğinde ise örneklerin gözenekliliğinin daha yüksek olduğu, metal dağılımının homojen ve kristal yapısının daha iyi olduğu görülmüştür.

Anahtar Kelimeler: Biyokütle, Karbon Malzeme, Katalizör, Destek.

\section{Production and Characterization of Bio-based Materials as Support for Precious Metal Catalysts}

\begin{abstract}
Catalysts are one of the most important component that are used in a wide area in the chemical industry and increase the cost in the sector. Especially, the use of catalyst support material with precious metal catalyst is important in reducing the catalyst cost. Carbonaceous materials have been used in heterogeneous catalysis reactions as they provide the desired properties for catalyst support, and it is important that these materials can be obtained from a sustainable and renewable source such as biomass. In this study, production of bio-based material from fir wood sawdust and using these materials as carbonaceous catalyst support materials were investigated. Biochar was produced via carbonization while hydrochar was produced via hydrothermal carbonization among the thermochemical processes. Precious metals Pt and Pd was loaded to biomass, biochar and hydrochar as wt.1\%. The physicochemical and surface properties of the obtained catalyst samples were examined using different techniques. It was determined that the biomass did not have suitable properties for direct use as catalyst support. When the catalyst properties of the metal loaded biomass and hydrochar were examined, it was seen that the porosity of the samples was higher, the metal distribution was homogeneous and the crystal structure was better.
\end{abstract}

Keywords: Biomass, Carbon Material, Catalyst, Support.

*Sorumlu Yazar: elif.yaman@bilecik.edu.tr 


\section{Giriş}

Kimya sektöründe geniş bir alanda kullanılan katalizörler, farklı teknolojilerin geliştirilmesinde önemli bir rol oynamaktadır. Sadece kömür, doğalgaz ve petrol gibi geleneksel karbonlu hammaddelerin değil, aynı zamanda biyokütle gibi yenilenebilir hammaddelerin de yakitlar ve kimyasallar gibi katma değerli ürünlere dönüştürülmesinde katalizörler kullanılmaktadır (Hopa ve Yilmaz, 2019; Bartholomew ve Farrauto, 2011). Küresel katalizör pazarının yaklaşık 15 milyar dolar olduğu tahmin edilmektedir (O’Neill vd., 2015). Küresel gayri safi yurt içi hasıla (GSYİH)'nın \% 35'inden fazlası ise katalitik teknolojilerle ilişkilendirilmiştir (Armor vd., 2008) ve endüstriyel ürünlerin \% 95'inin katalitik süreçlerle üretildiği bilinmektedir (O’Neill vd., 2015 ).

Katalizörler genel olarak homojen, heterojen ve enzimatik olarak sinıflandırılırlar, her birinin avantajları ve dezavantajları vardır (Balagurumurthy vd., 2015). Homojen katalizörlerin aktif bölgesi ile biyokütle molekülleri arasındaki istenmeyen kontrolsüz reaksiyonlar, istenen ürünlerin üretimini engeller. $\mathrm{Bu}$ nedenle, heterojen katalizörler, i) hidrotermal kararlılık, ii) yeniden kullanılabilirlik iii) zenginleştirilmiş gözeneklilik iii) ayarlanabilir yüzey alanı ve yapı iv) katı fazda oldukları için üründen kolayca ayrilabilmesi gibi özellikleri nedeniyle tercih edilirler (Sudarsanam vd., 2019; Taarning vd., 2011).

Biyokütleden dönüştürülen karbon tabanlı çeşitli katalizörler, yakıt üretimi için verimli heterojen katalizörler olarak araştırılmaktadır. Karbon tabanlı malzemeler, katalizör desteği için arzu edilen özellikleri nedeniyle heterojen kataliz reaksiyonlarında uzun süredir kullanılmaktadır ve bu malzemeler birçok endüstriyel uygulamada doğrudan katalizör olarak da kullanılabilmektedir (Lee vd., 2017). Biyochar veya hidrochar, değişik biyokütle kaynaklarından termokimyasal tekniklerle üretilen ve çevre dostu karbon olarak adlandırılan kömür benzeri bir karbonlu malzemelerdir (Balajii ve Niju, 2019). Biyokütlenin oksijensiz ortamda 1sıl bozunması ile elde edilen biyocharın katalizör ya da katalizör destek malzemesi olarak kullanılabilmesi için araştırmacılar farklı modifikasyon çalışmaları ile biyocharın aktivasyon kapasitelerini artırma çalışmalarını sürdürmektedirler (Chi vd., 2020; Ok vd., 2015; Qian vd., 2015). Biyochar, karbon bakımından zengin ve yüksek gözenekliliğe sahip bir malzemedir bu özellikleri nedeniyle de diğer katı karbon katalizörlerin pahalı olması ve çevre dostu olmaması gibi bazı bilinen olumsuzluklarına umut verici bir alternatiftr. Buna ek olarak, biyocharın fizikokimyasal özellikleri asit ya da baz muamelesi veya karbonizasyon yoluyla değiştirilebilir (Rajapaksha vd., 2016; Kambo ve Dutta, 2015). Fizikokimyasal özelliklerinin istenen şekilde modifiye edilebilmesi, biyocharın katalitik malzemeler olarak doğru bir şekilde değerlendirilmesi açısından önemlidir (Anto vd., 2021). Biyochar veya hidrochar çeşitli biyokütle dönüştürme işlemlerinde i) fermentasyon ile biyoetanol üretimi, ii) transesterifikasyon ile biyodizel üretimi, iii) gazlaştırma ile temiz sentez gazı üretimi, iv) piroliz ile biyo-yağ üretimi, v) katran azaltma ve vi ) daha iyi yakıt özellikleri için yakıt iyileştirme reaksiyonlarında heterojen katalizörler olarak kullanılmaktadır (Cheng and Li, 2018; Xiong vd., 2017).

Yapılan bu çalışmada, literatüre katkı sağlaması amacıyla biyokütle, hidrochar ve biyochar örneklerinin katalizör destek malzemesi olarak kullanılabilirliği araştırılmıştır. Öncelikle biyokütlenin karakterizasyon çalışmaları yapılmış, ardından üretilen hidrochar ve biyochar örneklerine $\mathrm{Pd}$ ve Pt metalleri yüklenmiştir.

\section{Materyal ve Metot}

\subsection{Materyal}

Biyotabanlı malzemelerin geliştirilmesi için biyokütle kaynağı olarak göknar ağacı talaşı (G) seçilmiştir. Fabrika atığı olarak temin edilen göknar ağacı talaşı, elek sarsma cihazı ve elek seti (RETSCH) kullanılarak yedi farklı parçacık boyutu $(\mathrm{Dp}<0,212 ; \quad 0,212<\mathrm{Dp}<0,425 ; \quad 0,425<\mathrm{Dp}<0,625$; $0,625<\mathrm{Dp}<0,800 ; 0,800<\mathrm{Dp}<1,25 ; 1,25<\mathrm{Dp}<1,8 ; 1,8<\mathrm{Dp}) \quad$ elde edilmek üzere elenmiştir. Göknar ağacı talaşının karakterizasyonu çalışmalarında (i) nem (Sartorius, MA 150), (ii) kül (ASTM D 1102-84), (iii) uçucu madde (ASTM E 897-82) miktar tayini gerçekleştirilmiştir. Ayrıca göknar ağacı talaşının sahip olduğu karbon, hidrojen, oksijen ve azot miktarının tayin edilmesi için elementel analiz (LECO CHN), içerdiği fonksiyonel grupların belirlenmesi için FT-IR (Fourier dönüşümlü kızılötesi spektroskopisi, Perkin Elmer Spectrum 100) ve yüzey morfolojisinin belirlenmesi için SEM (Taramalı Elektron Mikroskobu, Zeiss Supra 40VP) kullanılarak karakterizasyon çalışmaları tamamlanmıştır.

\subsection{Hidrochar ve Biyochar Üretimi}

Göknar ağacı talaşının "hidrotermal karbonizasyonu” için bilgisayar kontrollü, yüksek sıcaklığa ve yüksek basınca çıkabilen 1 L hacmindeki kesikli bir otoklav reaktör (PARR 4575B Reaktör) kullanılmıştır. Hidrotermal karbonizasyon sıcaklığı $190{ }^{\circ} \mathrm{C}$, katı/su oranı kütlece 1:5, basınç 5 bar ve reaksiyon süresi $10 \mathrm{dk}$ olarak sabit tutulmuştur. Reaksiyon sonunda katı-sıvı karışımı reaktörden alınarak süzme işlemi uygulanmıştır. Ayrılan katı faz, önce oda koşullarında sonra da 24 saat boyunca $105{ }^{\circ} \mathrm{C}$ etüvde kurutulmuştur. Elde edilen hidro-char HC olarak kodlanmıştır.

Göknar ağacı talaşının "karbonizasyon işlemi” ise kül fırında (Magmetherm) gerçekleştirilmiştir. Ağzı kapalı toprak kaplara yerleştirilen göknar ağacı talaşı örneği, $20{ }^{\circ} \mathrm{C} / \mathrm{dk}$ 1sıtma hızında $550{ }^{\circ} C^{\prime}$ ye 1 sitılmış ve bu sicaklıkta $10 \mathrm{dk}$ bekletilerek oda sıcaklığına soğutulmuştur. Elde edilen biyo-char BC olarak kodlanmıştır.

\subsection{Biyokütle, Hidro-char ve Biyo-char Destek Malzemelerine Pd ve Pt Metallerinin Yüklenmesi}

$\mathrm{G}, \mathrm{HC}$ ve $\mathrm{BC}$ öncelikle \%10'luk $\mathrm{HNO}_{3}$ ile $80^{\circ} \mathrm{C}$ sicaklıkta 3 saat muamele edilmiştir. Asit ile muamele edilen bu örnekler sırası ile AG, AHC ve ABC olarak adlandırılmıştır. Daha sonra paladyum miktarı \%1 olacak şekilde $\mathrm{PdCl}_{2}$ tuzu tartılmış ve bu $\mathrm{Pd}$ kaynağı olan bu tuz $1 \mathrm{M}^{\prime} \mathrm{l}_{\mathrm{k}} 12 \mathrm{~mL} \mathrm{HCl}$ çözeltisi içerisinde çözülmüştür. AG, $\mathrm{AHC}$ ve $\mathrm{ABC}$ destek malzemelerinden 1'er gram tartılmış ve $\mathrm{Pd}$ çözeltisi katılar üzerine damla damla eklenmiştir. $30{ }^{\circ} \mathrm{C}$ sıcaklıkta 20 saat bekletilen karışıma, bu süre sonunda bazik pH elde edilene kadar \%30'luk $\mathrm{NaOH}$ çözeltisi eklenmiştir. Bazik haldeyken 3 saat boyunca $30{ }^{\circ} \mathrm{C}$ sicaklıkta karıştırılmaya devam edilmiş, ardından $60^{\circ} \mathrm{C}$ 'ye 1 sıttılmış ve 800 $\mu \mathrm{L} \% 37^{\prime}$ lik formaldehit eklenmiştir. 2 saat boyunca $60{ }^{\circ} \mathrm{C}$ 'de bekletilen karışım süzülmüş ve $5 \mathrm{kez}$ saf su ile yıkanmıştır. Süzüntüden ayrılan katalizör oda sıcaklığında kurutulmuş ve karakterizasyona hazır hale getirilmiştir. Elde edilen katalizörler sırası ile \%1Pd-G, \%1Pd-HC ve \%1Pd-BC olarak adlandırılmıştır (Casoni vd., 2018; Kubota vd., 2012; Arcanjo vd., 2017).

Pt metali yüklü biyotabanlı malzeme sentezinde ilk basamak olarak platin miktarı \%1 olacak şekilde $\left[\mathrm{Pt}\left(\mathrm{NH}_{3}\right)_{4}\right]\left(\mathrm{NO}_{3}\right)_{2}$ tuzu tartılmış ve Pt kaynağı olan bu tuz 10 mL saf suda çözünmüştür. 
AG, AHC ve ABC destek malzemelerinden 1'er gram tartılmış ve Pt çözeltisi katılar üzerine damla damla $50{ }^{\circ} \mathrm{C}$ 'de eklenmiştir. Ardından $800 \mu \mathrm{L} \% 37^{\prime}$ lik formaldehit eklenip, bu sicaklıkta bir saat bekletilmiştir. Çözeltiden süzülerek ayrılan katı 5 kez saf su ile yıkanmış ve $100^{\circ} \mathrm{C}$ 'deki etüvde 2 saat boyunca kurutulmuştur (Arcanjo vd., 2017; He vd., 2008; Liang vd., 2009). Elde edilen katalizörler sirası ile \%1Pt-G, \%1Pt-HC ve \%1Pt-BC olarak adlandırılmıştır

\subsection{Katalizör Karakterizasyonu}

Elde edilen katalizör örneklerinin sahip olduğu fonksiyonel grupların belirlenmesi amaciyla FTIR spektroskopisi kullanılmıştır. Örneklerin spektrumları $4000-380 \mathrm{~cm}^{-1}$ dalga boyu aralığında, $0,4 \mathrm{~cm}^{-1}$ çözünürlük ile zayıf toplam frekans (ATR) modülü kullanılarak elde edilmiştir. SEM görüntüleri alınmadan önce numunelerin iletkenliğinin sağlanması için platin ile kaplama işlemi uygulanmıştır. Kaplama cihazında (Quorum, Q300 model) Au/Pd kaynağı altında 1 dakika boyunca kaplanan örneklerin kaplama kalınlığı yaklaşık 100 nm'dir. Katalizör örneklerine uygulanan tüm SEM çekimlerinde, $15 \mathrm{kV}$ hızlandırma voltajı (EHT), $\sim 10 \mathrm{~mm}$ çalışma mesafesi (WD), farklı büyütme oranları ve ikincil elektron (SE) görüntüleme yöntemi kullanılmıştır. Yüzey alanı ölçüm analizleri Brunauer, Emmet ve Teller yüzey alanı tayin cihazı (BET, MicromeriticsASAP2020) kullanılarak yapılmıştır. BET yüzey alanları $\left(\mathrm{m}^{2} / \mathrm{g}\right)$, gözenek boyutu (nm), mikro gözenek ve mezo-makro gözenek hacimleri $\left(\mathrm{cm}^{3} / \mathrm{g}\right)$ çok noktalı BET analizi ile belirlenmiştir.
Analizden önce uygulanan degaz işleminde sıcaklık $300{ }^{\circ} \mathrm{C}$ ve süre 360 dk'dır. Katalizörlerin kristal yapı karakterizasyonları XIşını Kırınım Cihazı (XRD, Panalytical-Empyrean) kullanılarak gerçekleştirilmiştir. Katalizörlere uygulanan XRD analizinde $\mathrm{CuK} \alpha(\lambda=0,15405 \mathrm{~nm})$ radyasyonu kullanılarak, $2 \theta$ açı aralığı 10 $90^{\circ}$ olacak şekilde $2^{\circ} / \mathrm{dk}$ tarama hızında X-1şını kırınım desenleri elde edilmiştir.

\section{Araştırma Sonuçları ve Tartışma}

\subsection{Hammaddeye ait karakterizasyon sonuçları}

Talaş halinde temin edilen göknar ağacı talaşı oda koşullarında 48 saat kurutulduktan sonra yedi farklı parçacık boyutu elde edilmek üzere elenmiştir. Elekler üzerinde kalan miktarlar ile hesaplanan kütle kesirlerinden göknar ağacı talaşının ortalama parçacık boyutu $0,948 \mathrm{~mm}$ olarak hesaplanmıştır. Göknar ağacı talaşına uygulanan ön analiz, elementel analiz, H/C, $\mathrm{O} / \mathrm{C}$ oranları ve 1 sıl değer sonuçları sonuçları Tablo 1'de verilmiştir. Göknar ağacı talaşı ağırlıç̧a \%7,01 nem ve \%0,21 kül içermektedir. Uçucu madde miktarı \% 80,74 olan göknar ağacı talaşının sabit karbon miktarı \%12,04 olarak hesaplanmıştır. Göknar ağacı talaşının karbon içeriği kütlece \%41,34 iken, hidrojen içeriği kütlece $\% 6,86$ ve oksijen içeriği ise kütlece \%51,56 olarak bulunmuştur. Göknar ağacı talaşının sahip olduğu 1sıl değer ise elementel analiz sonuçları ve Dulong formülü (Yaman vd., 2021) kullanılarak 14,58 MJ/kg olarak hesaplanmıştır.

Tablo 1. Göknar ăgacı talaşının ön analiz ve elementel analiz sonuçları

\begin{tabular}{lc|lc}
\hline Analiz & Değer & Analiz & Değer \\
\hline Nem (\%) & 7,01 & Karbon (\%) & 41,34 \\
Kül (\%) & 0,21 & Hidrojen (\%) & 6,86 \\
Uçucu Madde (\%) & 80,74 & Azot (\%) & 0,24 \\
Sabit Karbon (\%) & 12,04 & Oksijen (\%) & 51,56 \\
& & H/C & 1,99 \\
& & O/C & 0,91 \\
& & Is1l Değer (MJ/kg) & 14,58 \\
\hline
\end{tabular}

aSabit Karbon= 100-(Nem+Kül+Uçucu Madde)

${ }^{\mathrm{b}}$ Farktan

Göknar ağacı talaşının farklı fonksiyonel gruplara sahip olduğunu gösteren FTIR spektrumu Şekil 1'de verilmiştir. 3356 $\mathrm{cm}^{-1}$ civarında gözlenen geniş pik hidroksil grubunu ifade etmektedir. 2924-2856 $\mathrm{cm}^{-1}$ de yer alan bölge metil ve metilen gruplarında yer alan $\mathrm{C}-\mathrm{H}$ gerilme titreşimlerine aittir. Karbonil grupları $(\mathrm{C}=\mathrm{O}), 1742 \mathrm{~cm}^{-1}$ bölgesinde yer almaktadır. Metil, metilen ve karbonil gruplarına ait pikler göknar ağacı talaşında belirgin olarak gözlenmektedir. $1241 \mathrm{~cm}^{-1}$ bölgesinde ve 1036 $\mathrm{cm}^{-1}$ bölgesinde görülen en şiddetli pik alkol, fenol, eter ve ester gruplarına ait $\mathrm{C}-\mathrm{O}$ gerilme titreşimine aittir. Benzen türevlerindeki C-H bağının düzlem dışı eğilme titreşimi 894$841 \mathrm{~cm}^{-1}$ de yer almaktadır (Khan vd., 2018). Bu bağların eğilme titreşimine ait piklerin göknar ağacı talaşında görülmesi, biyokütle yapısında benzen türevlerinin olduğunu e-ISSN: 2148-2683 göstermektedir (Maliutina vd., 2017). Göknar ağacı talaşının yüzey morfolojisinin belirlenmesi için $100 x$ büyütme ve $500 x$ büyütmelerde alınan SEM görüntüleri sırası ile Şekil 2 (a) ve Şekil 2 (b)'de verilmiştir. SEM görüntülerinden göknar ağacı talaşının kompleks ve çok tabakalı lifli lignoselülozik yapıda olduğu fakat gözenekliliğinin çok yüksek olmadığı görülmektedir.

\subsection{Elde edilen katalizörlere ait karakterizasyon sonuçları}

Kütlece \%1 Pt ve \%1 Pd yüklenen $\mathrm{G}, \mathrm{BC}$ ve $\mathrm{HC}$ örneklerine ait FT-IR spektrumu sırası ile Şekil 3 (a) ve Şekil 3 (b)'de verilmiştir. 1000-900 $\mathrm{cm}^{-1}$ bölgesinde gözlemlenen ve 
yapıdaki C-O bağı varlığını gösteren piklerin \%1Pt-BC ve $\% 1 \mathrm{Pd}-\mathrm{BC}$ örneklerinde görülmediği belirlenmiş ve bu bağların ısıl işlem sırasında kırıldığı belirlenmiştir. Ayrıca alkol, fenol ve karboksilik asitlerin varlığını gösteren ve $3500-3200 \mathrm{~cm}^{-1}$ bölgesinde gözlemlenen geniş ve yaygın - $\mathrm{OH}$ bandının şiddeti ise yine $\% 1 \mathrm{Pt}-\mathrm{BC}$ ve $\% 1 \mathrm{Pd}-\mathrm{BC}$ örneklerinde azalmaktadır. $\% 1 \mathrm{Pt}-\mathrm{G}, \% 1 \mathrm{Pt}-\mathrm{HC}, \% 1 \mathrm{Pd}-\mathrm{G}$ ve \%1Pd-HC örneklerinden farkl olarak \%1Pt-BC örneğinde $1584 \mathrm{~cm}^{-1}$ ve \%1Pd-BC örneğinde ise $1573 \mathrm{~cm}^{-1}$ bölgesinde pikler görülmektedir. $1600-1500 \mathrm{~cm}^{-1}$ bölgesindeki bu pikler yapıdaki $\mathrm{C}=\mathrm{O}$ bağlarını göstermektedir.

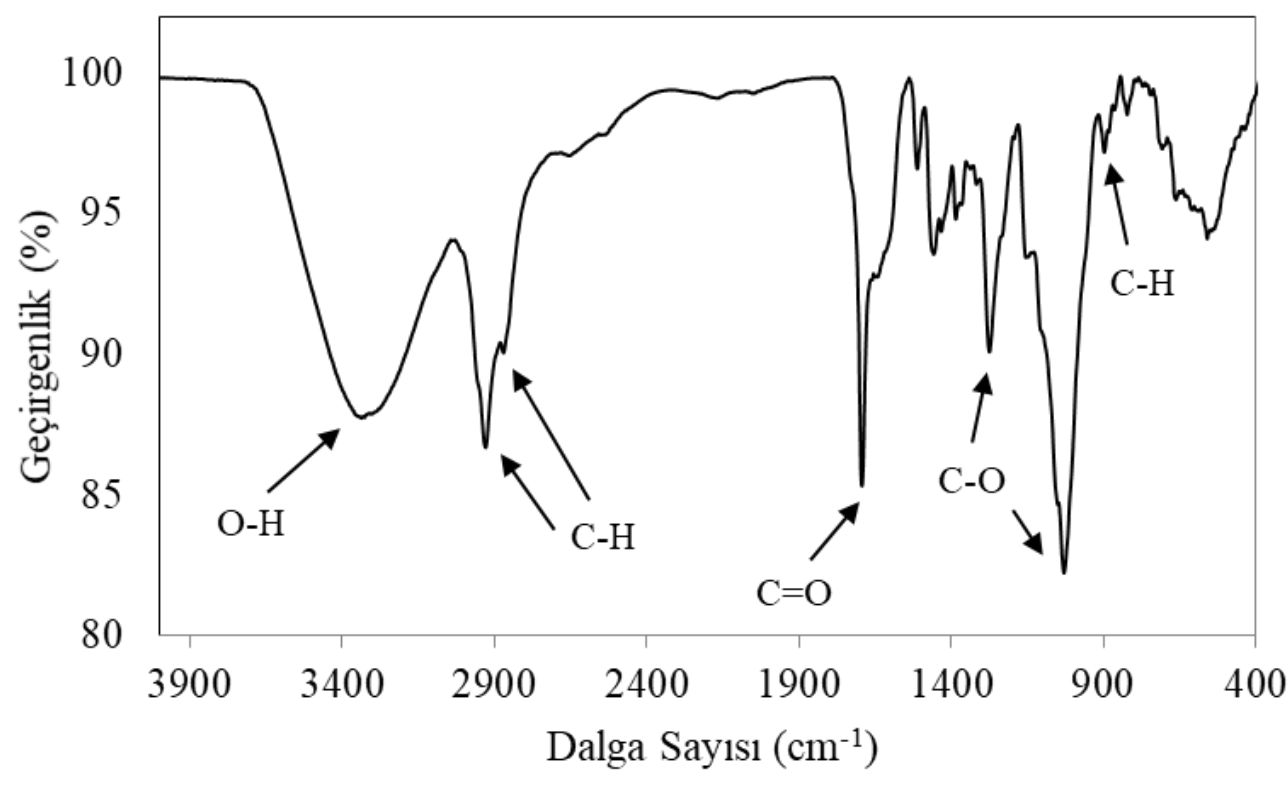

Şekil 1. Göknar ăgacı talaşının FTIR spektrumu
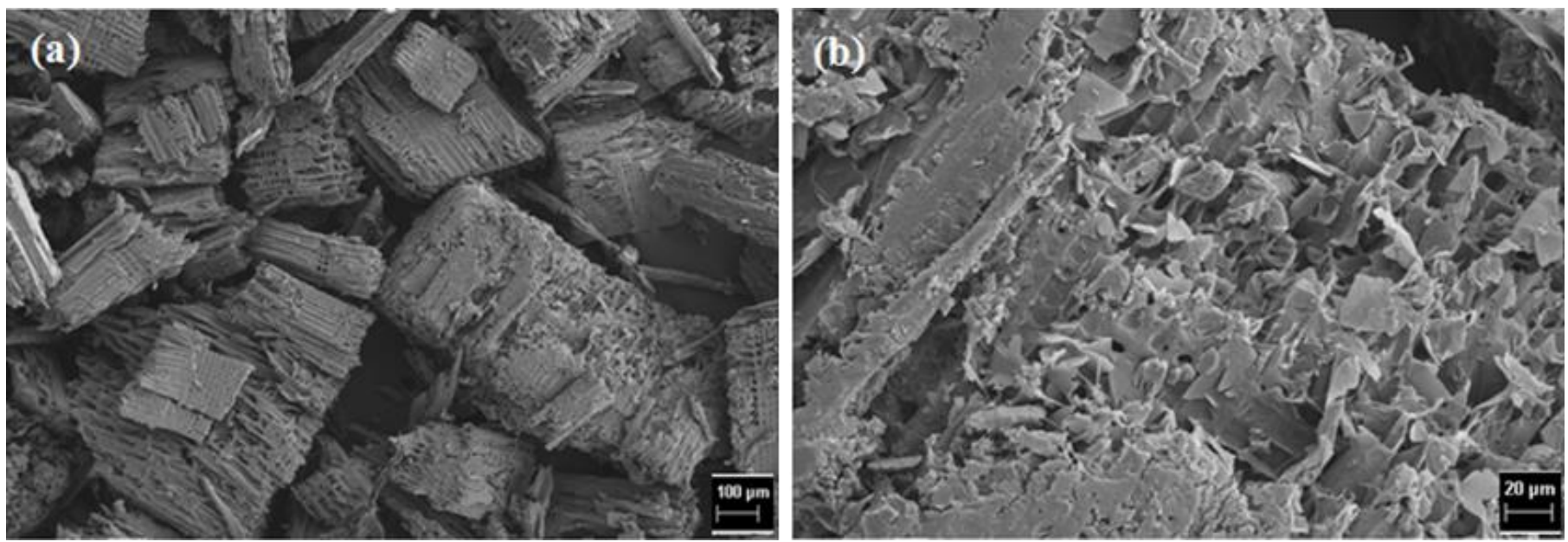

Şekil 2. Göknar ăgacı talaşına ait (a) 100x (b) 500x büyütmelerde alınmış SEM görüntüleri 

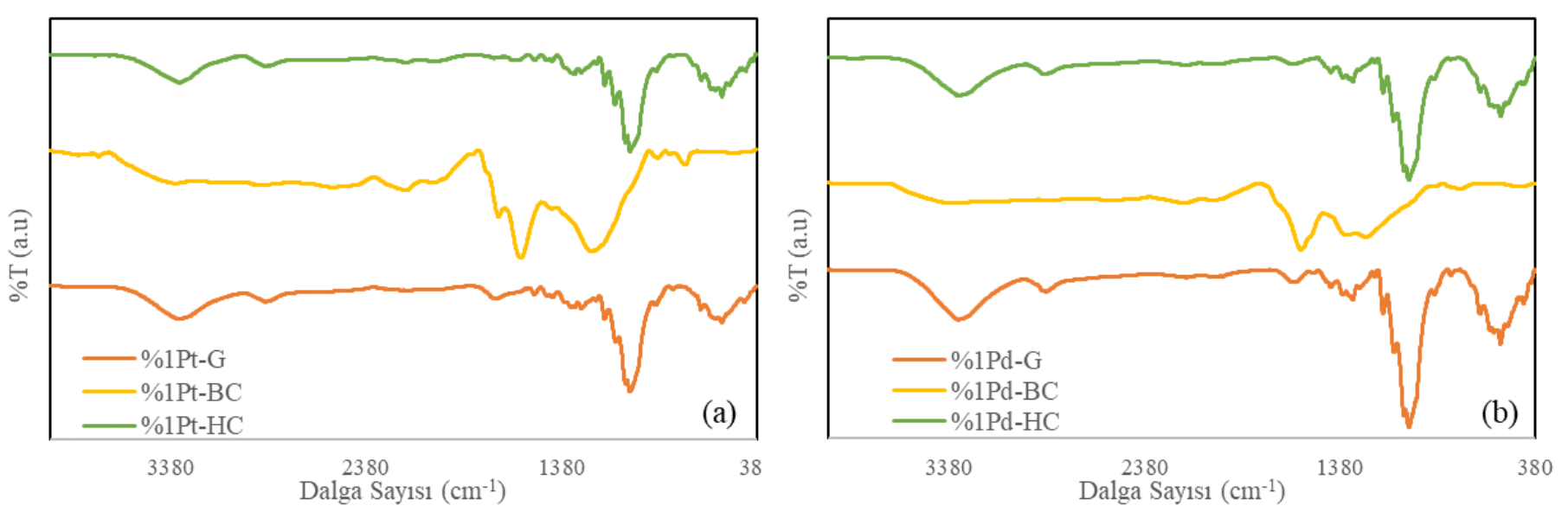

Şekil 3. (a) Kütlece \%1 Pt yüklenmiş katalizörlerin (b) Kütlece \%1 Pd yüklenmiş katalizörlerin FTIR spektrumları

Kütlece $\% 1 \mathrm{Pt}$ ve $\% 1 \mathrm{Pd}$ yüklenen $\mathrm{G}, \mathrm{BC}$ ve $\mathrm{HC}$ örneklerine ait BET analiz sonuçları Tablo 2'de verilmiştir. Pt yüklenen katalizörlerden en yüksek yüzey alana sahip olan katalizör $17,6335 \mathrm{~m}^{2} / \mathrm{g}$ BET yüzey alanına sahip olan \%1Pt-BC örneğidir. \%1Pt-G örneği mikrogözenekliliğe sahip değilken, mikro gözenekliliği de en yüksek olan katalizör $0,0064 \mathrm{~cm}^{3} / \mathrm{g}$ mikrogözenek hacmine sahip olan \%1Pt-BC örneğidir. Pd yüklenen katalizörlerden en yüksek yüzey alana sahip olan katalizör $0,8456 \mathrm{~m}^{2} / \mathrm{g}$ BET yüzey alanına sahip olan \%1Pd-HC örneğidir. Pd yüklenmiş katalizörlerden en yüksek mikrogözenek hacmine sahip olan katalizör örneği ise 0,0021 $\mathrm{cm}^{3} / \mathrm{g}$ mikrogözenek hacmi ile \%1Pd-BC örneğidir.

Tablo 2. \%1 Pt ve \% 1 Pd yüklenen katalizörlerin BET analiz sonuçları

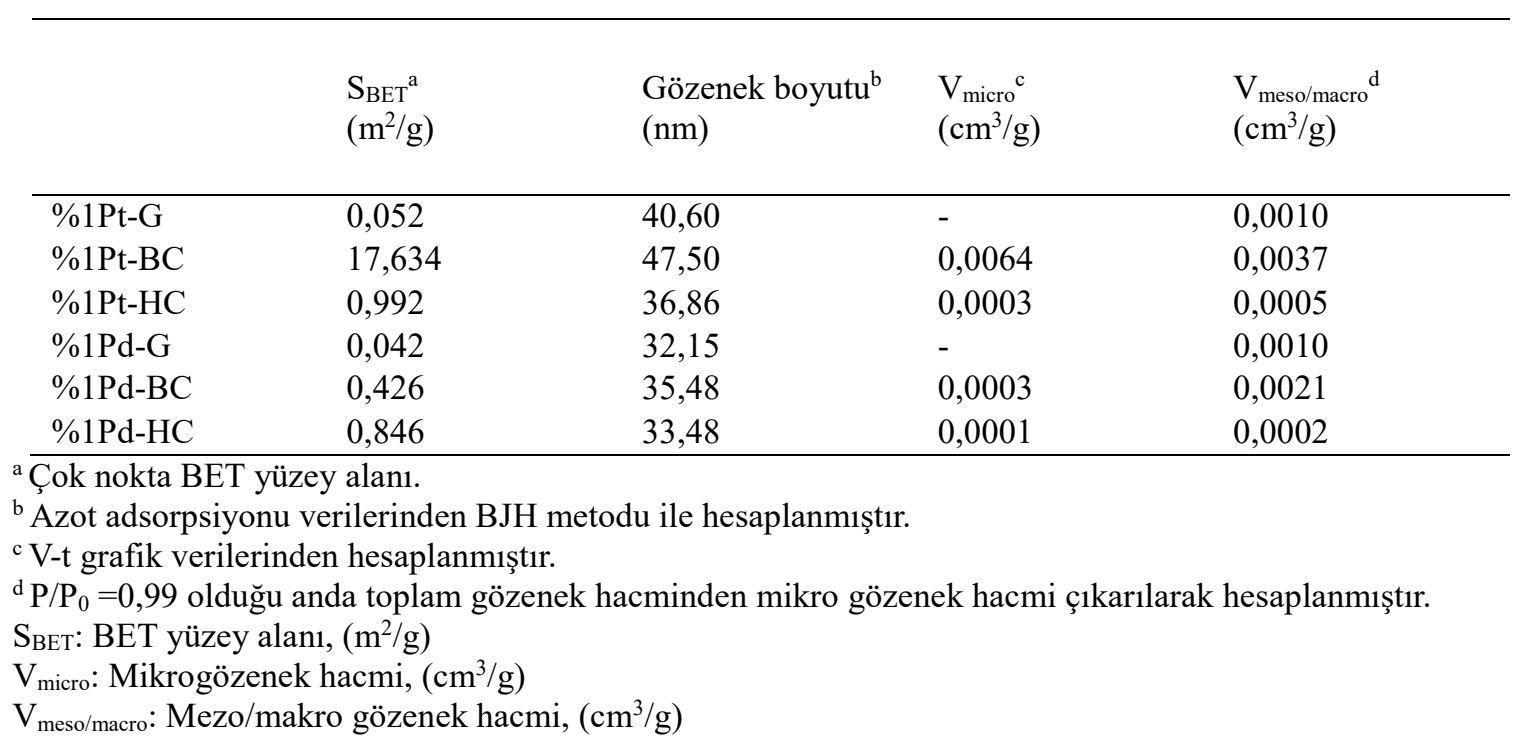

Kütlece \%1 Pt yüklenmiş katalizörlerin SEM görüntüleri ve elementel haritalama ile elde edilen Pt dağılımları Şekil 3'de, kütlece \%1 Pd yüklenmiş katalizörlerin SEM görüntüleri ve elementel haritalama ile elde edilen Pd dağılımları ise Şekil 4'te verilmiştir. \%1 Pt yüklenen katalizör destek malzemelerinden göknar ağacı talaşı (\%1Pt-G) ve göknar ağacı talaşının hidrocharına (\%1Pt-HC) yükleme yapıldığında, özellikle hidrocharda Pt dağılımının homojen olmadığı görülmektedir. Göknar ağacı talaşının biyo-charına (\%1Pt-BC) Pt yüklenmesi sonucu elde edilen katalizörde ise $\mathrm{Pt}$ dağ yüklenen katalizör destek malzemelerinin SEM görüntüleri kıyaslandığında, göknar ağacı talaşının biyocharına (\%1PdBC) Pd yüklenmesi ile parçacık boyutu daha küçük ve e-ISSN: 2148-2683 gözenekliliği daha yüksek olan bir katalizör elde edilmiştir. Ayrıca katalizör yüzeylerindeki Pd dağılımı incelendiğinde bu katalizör yüzeyinde Pd'nin homojen olarak dağıldığı görülmektedir.

\section{Sonuç}

Yapılan çalışmada, karbonlu malzeme üretimi için hammadde olarak göknar ağacı talaşı seçilmiştir. Gerçekleştirilen elementel analiz sonuçlarına göre hammaddenin kütlece \%41,34 karbon içerdiği ve karbonlu malzeme üretiminde kullanılmak için uygun olduğu belirlenmiştir. Ayrıca göknar ağacı talaşı kütlece \%80,37 uçucu 
madde içeriği ile biyokütlenin termokimyasal işlemlerle dönüştürülmesi için de uygun bir hammaddedir. Sentezlenen katalizörlerin gözeneklilik analiz sonuçlarına göre en yüksek BET yüzey alanına sahip olan örneklerin her bir farklı metal yüklemesi için Pt-BC ve Pd-HC olduğu belirlenmiştir. Ayrıca SEM ve elementel haritalama görüntülerinden homojen $\mathrm{Pt}$ dağılımının Pt-BC; homojen Pd dağılımının ise Pd-BC ve PdHC örneklerinde elde edildiği görülmektedir. Sentezlenen karbonlu malzemelerin amorf yapıda oldukları fakat Pt-BC örneğinde metalik Pt pikinin gözelndiği, $\mathrm{Pd}-\mathrm{BC}$ örneğinde ise metalik Pd pikinin gözlendiği belirlenmiştir. Elde edilen tüm sonuçlar kıyaslandığında biyokütlenin katalizör desteği olarak doğrudan kullanılması için uygun fizikokimyasal ve yüzeysel özelliklere sahip olmadığı belirlenmiştir. Buna ek olarak, biyocharın destek malzemesi olarak kullanıldığı katalizörlerin gözeneklilik özelliklerinin daha iyi olduğu, metal dağılımının homojen olduğu ve kristal yapısının daha iyi olduğu görülmüştür. Göknar ağacı talaşının termokimyasal yöntemlerle dönüştürülerek üstün yüzey özelliklerine sahip biyo-char/hidro-char elde edilmesi ve bu gözenekli malzemelerin katalizör destek malzemesi olarak kullanılması biyokütlenin farklı bir uygulama alanında değerlendirilebilmesi için umut verici bir sonuçtur.

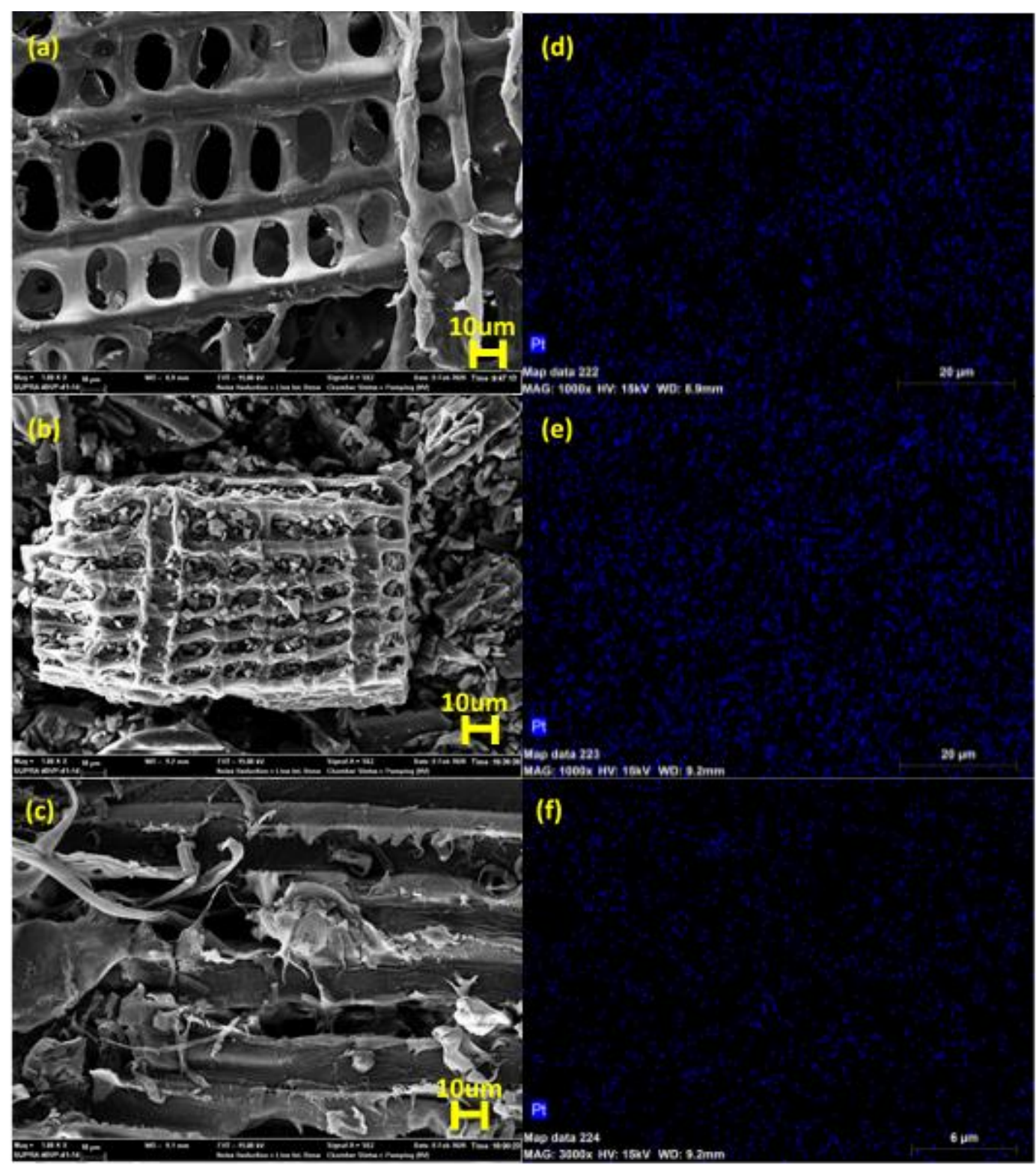

Şekil 3. Kütlece \%1 Pt yüklenmiş katalizörlerin SEM görüntüleri (a) \%1Pt-G (b) \%1Pt-BC (c) \%1Pt-HC ve elementel haritalama ile elde edilen Pt dağllimlarl (d) \%1Pt-G (e) \%1Pt-BC (f) \%1Pt-HC 


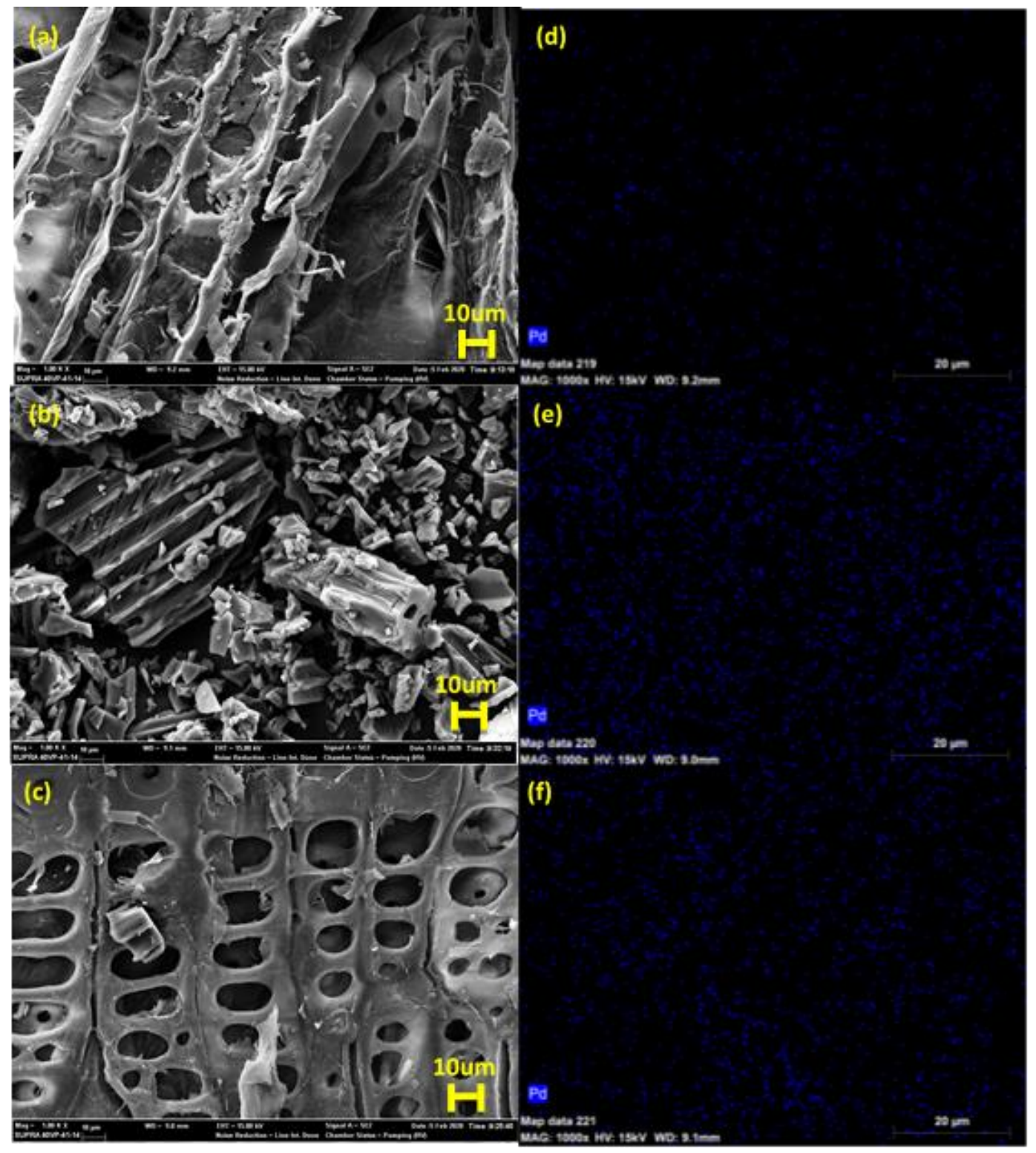

Şekil 4. Kütlece \%1 Pd yüklenmiş katalizörlerin SEM görüntüleri (a) \%1Pd-G (b) \%1Pd-BC (c) \%1Pd-HC ve elementel haritalama ile elde edilen Pd dağllimları (d) \%1Pd-G (e) \%1Pd-BC (f) \%1Pd-HC
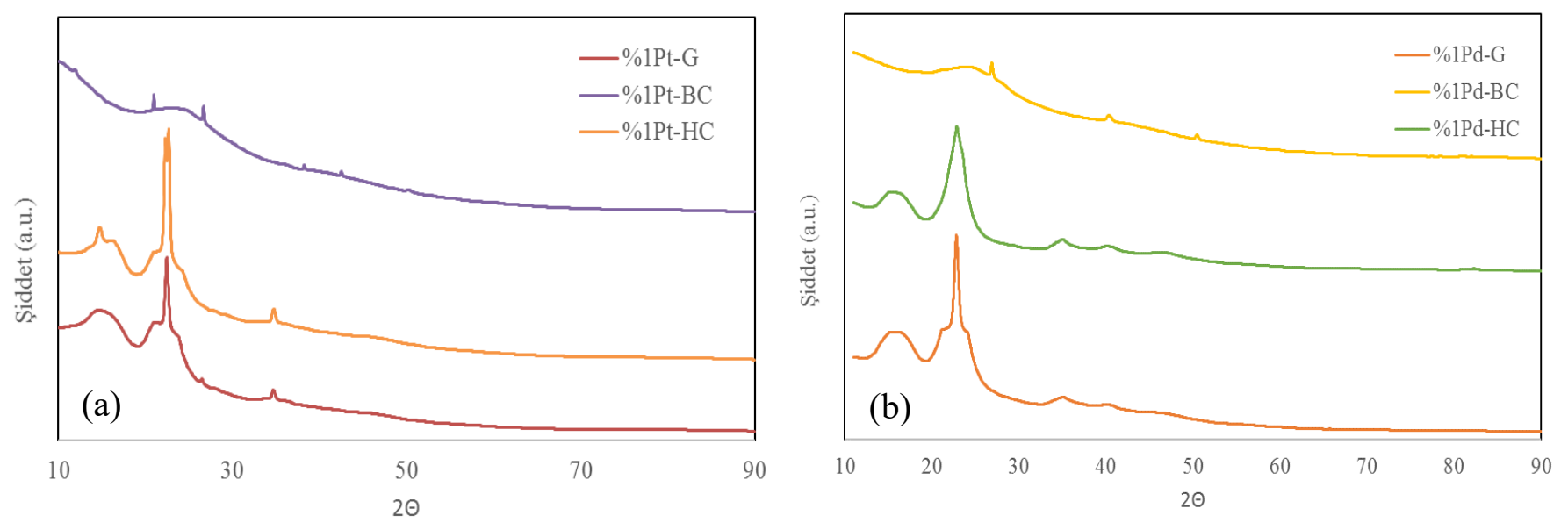

Şekil 5. (a) Kütlece \%1 Pt yüklenmiş katalizörlerin (b) Kütlece\%1 Pd yüklenmiş katalizörlerin XRD kurınım desenleri 


\section{Teșekkür}

Bu çalışma Bilecik Şeyh Edebali Üniversitesi Bilimsel Araştırma Projeleri Koordinatörlüğü tarafından 201802.BŞEÜ.28-01 numaralı proje ile desteklenmiştir.

\section{Kaynakça}

Anto, S., Sudhakar, M. P., Ahamed, T. S., Samuel, M. S., Mathimani, T., Brindhadevi, K., \& Pugazhendhi, A. (2021). Activation strategies for biochar to use as an efficient catalyst in various applications. Fuel, 285, 119205.

Arcanjo, M. R. A., Silva Jr, I. J., Rodríguez-Castellón, E., Infantes-Molina, A., \& Vieira, R. S. (2017). Conversion of glycerol into lactic acid using Pd or Pt supported on carbon as catalyst. Catalysis Today, 279, 317-326.

Armor, J., Farrauto, R., \& Iglesia, E. (2008). What is catalysis. The North American Catalñysis Society (NACS) http: www. nacatsoc//org/what. asp.

ASTM (1983), Standart test method for volatile matter in analysis sample refuse derived fuel-3, In ASTM Annual Book of Ame. Soc. for Testing and Materials Standarts, Easton, M.D., USA, E-897-82.

ASTM (1983), Standart test method for ash in wood, In ASTM Annual Book of Ame. Soc. for Testing and Materials Standarts, Easton, M.D., USA, D-1102-84.

Balagurumurthy, B., Singh, R., \& Bhaskar, T. (2015). Catalysts for thermochemical conversion of biomass. In Recent Advances in Thermo-Chemical Conversion of Biomass (pp. 109-132). Elsevier.

Balajii, M., \& Niju, S. (2019). Biochar-derived heterogeneous catalysts for biodiesel production. Environmental Chemistry Letters, 1-23.

Bartholomew, C. H., \& Farrauto, R. J. (2011). Fundamentals of industrial catalytic processes. John Wiley \& Sons.

Casoni, A. I., Hoch, P. M., Volpe, M. A., \& Gutierrez, V. S. (2018). Catalytic conversion of furfural from pyrolysis of sunflower seed hulls for producing bio-based furfuryl alcohol. Journal of Cleaner Production, 178, 237-246.

Cheng, F., \& Li, X. (2018). Preparation and application of biochar-based catalysts for biofuel production. Catalysts, $8(9), 346$.

Chi, N. T. L., Anto, S., Ahamed, T. S., Kumar, S. S., Shanmugam, S., Samuel, M. S., \& Pugazhendhi, A. (2020). A review on biochar production techniques and biochar based catalyst for biofuel production from algae. Fuel, 119411.

De Araujo, J. C., Sousa, C. B., Oliveira, A. C., Freire, F. N., Ayala, A. P., \& Oliveira, A. C. (2010). Dehydrogenation of ethylbenzene with $\mathrm{CO} 2$ to produce styrene over $\mathrm{Fe}$ containing ceramic composites. Applied Catalysis A: General, 377(1-2), 55-63.

He, S., Sun, C., Du, H., Dai, X., \& Wang, B. (2008). Effect of carbon addition on the Pt-Sn $/ \gamma-\mathrm{Al}_{2} \mathrm{O}_{3}$ catalyst for long chain paraffin dehydrogenation to olefin. Chemical Engineering Journal, 141(1-3), 284-289.

Hopa, D. Y., \& Yılmaz, N. (2019). Haşhaş Kapsülü Küspesinin Sabit Yataklı Reaktörde Katalitik Pirolizi. Avrupa Bilim ve Teknoloji Dergisi, (17), 581-588.

Kambo, H. S., \& Dutta, A. (2015). A comparative review of biochar and hydrochar in terms of production, physicochemical properties and applications. Renewable and Sustainable Energy Reviews, 45, 359-378.

e-ISSN: 2148-2683
Khan, A. S., Man, Z., Bustam, M. A., Nasrullah, A., Ullah, Z., Sarwono, A., Muhammad, N. (2018). Efficient conversion of lignocellulosic biomass to levulinic acid using acidic ionic liquids. Carbohydrate polymers, 181, 208-214.

Kubota, T., Ogawa, H., Okamoto, Y., Misaki, T., \& Sugimura, T. (2012). Preparation of Pd/C designed for chiral modified catalyst: Comparison with $\mathrm{Pd} / \mathrm{TiO} 2$ in enantioselective hydrogenation of $\alpha$-phenylcinnamic acid. Applied Catalysis A: General, 437, 18-23.

Lee, J., Kim, K. H., \& Kwon, E. E. (2017). Biochar as a catalyst. Renewable and Sustainable Energy Reviews, 77, 70-79.

Liang, D., Gao, J., Wang, J., Chen, P., Hou, Z., \& Zheng, X. (2009). Selective oxidation of glycerol in a base-free aqueous solution over different sized Pt catalysts. Catalysis Communications, 10(12), 1586-1590.

Maliutina, K., Tahmasebi, A., Yu, J., \& Saltykov, S. N. (2017). Comparative study on flash pyrolysis characteristics of microalgal and lignocellulosic biomass in entrained-flow reactor. Energy Conversion and Management, 151, 426438.

Ok, Y. S., Chang, S. X., Gao, B., \& Chung, H. J. (2015). SMART biochar technology - a shifting paradigm towards advanced materials and healthcare research. Environmental Technology \& Innovation, 4, 206-209.

O’Neill, B. J., Jackson, D. H., Lee, J., Canlas, C., Stair, P. C., Marshall, C. L., \& Huber, G. W. (2015). Catalyst design with atomic layer deposition. Acs Catalysis, 5(3), 1804 1825.

Qian, K., Kumar, A., Zhang, H., Bellmer, D., \& Huhnke, R. (2015). Recent advances in utilization of biochar. Renewable and Sustainable Energy Reviews, 42, 10551064.

Rajapaksha, A. U., Chen, S. S., Tsang, D. C., Zhang, M., Vithanage, M., Mandal, S., \& Ok, Y. S. (2016). Engineered/designer biochar for contaminant removal/immobilization from soil and water: potential and implication of biochar modification. Chemosphere, 148, 276-291.

Sudarsanam, P., Peeters, E., Makshina, E. V., Parvulescu, V. I., \& Sels, B. F. (2019). Advances in porous and nanoscale catalysts for viable biomass conversion. Chemical Society Reviews, 48(8), 2366-2421.

Taarning, E., Osmundsen, C. M., Yang, X., Voss, B., Andersen, S. I., \& Christensen, C. H. (2011). Zeolite-catalyzed biomass conversion to fuels and chemicals. Energy \& Environmental Science, 4(3), 793-804.

Xiong, X., Iris, K. M., Cao, L., Tsang, D. C., Zhang, S., \& Ok, Y. S. (2017). A review of biochar-based catalysts for chemical synthesis, biofuel production, and pollution control. Bioresource technology, 246, 254-270.

Yaman, E., Ulusal, A. \& Uzun, B.B. (2021). Co-pyrolysis of lignite and rapeseed cake: a comparative study on the thermal decomposition behavior and pyrolysis kinetics. SN Applied Science, 3, 97. 